Wayne State University

DigitalCommons@WayneState

Communication Faculty Research Publications

Communication

$7-1-2007$

\title{
Private Sector Influence In The International Telecommunication Union
}

Patricia K. McCormick

Wayne State University, dz7089@wayne.edu

\section{Recommended Citation}

McCormick, Patricia K. "Private sector influence in the International Telecommunication Union." info: the journal of policy, regulation and strategy for telecommunications, information, and media 9.4 (2007): 70-80.

Available at: http://digitalcommons.wayne.edu/commfrp/4

This Article is brought to you for free and open access by the Communication at DigitalCommons@WayneState. It has been accepted for inclusion in Communication Faculty Research Publications by an authorized administrator of DigitalCommons@WayneState. 
NOTICE: This is the author's final manuscript version, post-peer-review, and formatted for archiving; a definitive version was subsequently published in info: the journal of policy, regulation and strategy for telecommunications, information, and media, 9(4). July 2007. pp. 70-80.

Available online at: http://dx.doi.org/10.1108/14636690710762147 


\title{
Private sector influence in the International Telecommunication Union
}

\author{
PATRICIA K. McCORMICK, Associate Professor, Howard University, Washington, DC, USA. \\ Corresponding author Patricia McCormick can be contacted at: pmccormick@howard.edu
}

\begin{abstract}
This paper aims to examine the influence of private corporations in the tripartite structure of the International Telecommunications Union (ITU): Telecommunications Standardization, Radiocommunication, and Telecommunications Development. The paper finds that, in the standardization sector, power has been effectively transferred from nation states to the private corporate sector since the approval process now enables standards to be approved by members of the study group that developed them, which is essentially the private sector. In the radiocommunication sector, the private sector continues to conduct much of the requisite technical work, but national governments are ultimately the decision makers and, further, it is difficult to distinguish between treaty and nontreaty work. In the development sector, the ITU seeks to create an enabling environment for private investment in developing countries and actively seeks to build private sector partnerships. In the long run the ITU may be unable to satisfy either its narrow corporate constituency or the vast majority of its developing country members. As the United Nations agency which coordinates satellite spacing and allocates access to the electromagnetic spectrum on an international basis, the ITU is the world's most prominent international telecommunications institution, so its structural modifications and membership changes are of great significance in a world increasingly dependent on a global grid of wired and wireless telecommunications networks.
\end{abstract}

In accord with the expanded embrace of neoliberalism, the reform and privatization of the telecommunications sector, a policy process which diffused rapidly globally throughout the 1990s, was accompanied by the restructuring of the world's most prominent international telecommunications institution, the International Telecommunication Union (ITU), the United Nations agency which coordinates satellite spacing and allocates access to the electromagnetic spectrum on an international basis. This article examines the ways in which the private sector has extended its influence in the three sectors of the ITU, which correspond to its main areas of activity: Telecommunication Standardization (ITU-T), Radiocommunication (ITU-R), and Telecommunications Development (ITU-D). The tripartite structure is a result of the Additional Plenipotentiary Conference, held in Geneva in 1992, which streamlined ITU activities after the Plenipotentiary Conference held in Nice in 1989 initiated an evaluation of ITU structures, operations, and resources and embarked on restructuring the organization to make it more responsive to its members in a market-based, privately controlled global telecommunications environment.
In conjunction with the structural modification of the ITU, its membership base has witnessed change as the organization actively seeks to attract more private sector, corporate participants. Although the ITU is still referred to as an inter-governmental organization, since it comprises almost all of the world's countries which are designated as members who alone retain full voting rights, it now encompasses more than 650 private companies from the telecommunication, broadcasting, and information technology sectors that are classified as sector members. The 1998 and 2002 Plenipotentiary Conferences focused on strengthening the participation of the private sector in the ITU, adopting several resolutions enhancing the rights of sector members, as well as measures to enable the ITU to match industry's time-frames and operational practices. Private sector members were also admitted on a provisional basis as observers at Council 2005 and 2006 sessions. Some contend that such progress in expanding the rights of the private sector has been meager, given the amount of effort extended over many years to increase their influence, and many segments of the global telecommunications industry, who could provide valuable expertise, still consider participating in the 
ITU to be irrelevant and unnecessary for expanding their operations as this can be attained through bilateral negotiations. Others, however, aver that in light of the increased private sector participation in ITU activities it is essential that the needs of developing countries remain at the forefront of the ITU agenda and do not succumb to corporate directives.

Developing countries constitute the majority of ITU members and the bulk of the world's populace to whom telecommunications services must be extended in order to reduce the global disparity in access to information technologies and services. As noted, the ITU enjoys near universal membership, but that does not equate to universal participation. Full participation in ITU fora presents a variety of complex impediments for many developing counties who lack sufficient knowledgeable and experienced staff to articulate and successfully lobby, if you will, for their needs and for the attainment of equitable management and development of "common heritage" principles as related to space (Vogler, 1995). This article thus seeks to assess the various views regarding private sector participation in the ITU as well as the ramifications of the private participants on the activities of the ITU's three divisions.

\section{METHODOLOGIES}

The work of international institutions is one of the most influential factors governing our world, with decisions generally made by representatives of ruling groups, thus its endeavors are biased in relation to those in power (Escobar, 1995). As Escobar (1995) writes, our knowledge is ideological in the sense that the international organization's conceptions and means of description represent the world as it is for those who rule it, rather than for those who are ruled. The relationship between the two is socially constructed by bureaucratic and textual mechanisms that are anterior to their interaction, though the interaction is presented as "facts", which can be categorized by professional discourse and presented in standardized ways (Escobar, 1995). Ethnomethodologists contend that institutional texts cannot be taken as objective records of external reality, but must be understood in relation to institutional uses and goals and in the context of their production and interpretation (Escobar, 1995). Institutional ethnography thus attempts to discern the ways in which institutional procedures shape or produce socioeconomic and sociocultural practices.

Since this research is interdisciplinary in nature with several contemporary, interrelated issues being examined, methodologically, this work attempts to employ institutional ethnography in conjunction with the case study, which draws upon multiple data sources to investigate a specific phenomenon. Multiple sources of evidence are the primary strength of case studies since they facilitate the development of converging lines of inquiry, a process of triangulation. This study, which employs economic, political, and communication concepts and theories, is based on three sources of evidence: documentation, archival records, and élite interviews. In gathering data, field research was conducted at the ITU in Geneva in the spring of 2005. Case studies are not generalizable to populations or universes, but to theoretical propositions, thus the goal of the research is to generate analytic generalizations regarding telecommunications reform and the restructuring of international regimes.

\section{REGIME ANALYSIS}

The ITU is an international regime concerned with space and spectrum, part of our global commons, like seas, watercourses, and the atmosphere. The military and commercial utilization of space does not, however, generate widespread pubic interest or extensive involvement of non-governmental organizations as do other environmental issues. Radio frequencies or satellite orbital slots cannot be depleted as can fish stocks or minerals, but they are a relatively scarce and inordinately valuable resource that engenders competition for the best slots and specific frequencies. Furthermore, the use of one particular transmitter can impinge on another, thus this interdependency requires international coordination in order to avoid damaging interference 
(Vogler, 1995). The ITU, virtually since its inception in 1865 to regulate international telegraphy networks, has been concerned with ensuring the orderly use of the electronic commons as its mandate has gradually expanded with the advent of each new technology, from voice telephony to communications satellites to the technological convergence that defines the present digital, telecommunications-based information era. The ITU can thus be defined as a common property resource regime.

A regime is traditionally defined as a form of governance which comprises a set of norms, principles, rules and decision-making procedures that govern a particular issue area, such as the use of the global commons (Vogler, 1995). While this work does not intend to delve into the theories of international regimes, it is nonetheless necessary to differentiate meritorious, but contrasting points of view. Neoliberals contend that interdependencies and mutual interests conspire to promote increased international cooperation. Certainly establishing a common property status for international space and airspace and creating international technical standards reduces the transaction costs of conducting commerce. This congruence of interest does not, however, devalue the validity of neorealist contentions that mutual interests are not sufficient for regime development. Neorealist proponents contend that the presence of a dominant state or group of states which has the power to impose acceptance of the regime and compliance on other states is essential, because the hegemonic state or grouping will only support an international regime if it acquires greater relative gains (Zacher and Sutton, 1996).

Indeed, when the USA joined the ITU in 1932 , it was able to extract a number of concessions to its interests in exchange for joining because many ITU members sought to include the American market in the multilateral fold (Drake, 2000). The USA as well as Canada had not earlier joined the predecessor to the ITU, the International Telegraph Union, since it had not wanted to nationalize or impose treaty obligations and rates on its private carriers. Although private carriers were allowed to participate in the adminis- trative conferences, albeit without voting rights, since 1871 , these intercontinental undersea cable companies were essentially forced to acquiesce to the national Post, Telephone, and Telegraph (PTT) authorities to secure operating rights. To facilitate the participation of countries with private carriers, the USA, in agreeing to join the ITU, required that the decision-making procedures be amended, and the designation of "recognized private operating entity" (RPOA) was thus developed (Drake, 2000).

The rights of private companies as sector members in the ITU have since gradually evolved, in accord with the domestic policies of the USA and other dominant states. Writes Lyall (1989), "the law of England as applied to maritime matters through the Admiralty Court had significant impact and became for most purposes international maritime law ... History, therefore, leads me to suspect that US Law may become international space law ... By reason of its technical skills, its domestic market and its entrepreneurial attitudes, the USA is a major leader in space matters. That 'lead' may result in much US law becoming the language in which problems are discussed and solved." Policy differences between the USA, England, and Japan withstanding, each state liberalized basic and non-basic services, allowed the interconnection of leased lines as well as the reselling of capacity on leased lines, and permitted private firms in international cable and satellite markets, and in lieu of such changes and pressure from these hegemonic powers, the ITU officially retracted its restrictions against the reselling of leased lines in the early 1990s, which in turn enabled the development of competition in the traditional PTT market structures (Zacher and Sutton, 1996).

Liberalization of telecommunications as a domestic policy also led, at the international level, to the introduction of trade in services into the General Agreement for Tariff and Trade (GATT) Uruguay Round 1986-1994. The series of accords that were approved in April 1994 included a General Agreement in Trade in Services (GATS) and a Telecommunications Annex. Adherents to these GATT Agreements went on to establish within the institutional body of the 
World Trade Organization (WTO), which effectively succeeded GATT, an Agreement on Basic Telecommunications and a Reference Paper, which placed national regulations in the multilateral arena for the first time. These institutional changes support Cowhey's (1990) contentions that domestic politics are the primary source of regime change as hegemonic players influence the change of institutional structures, affect the centralization of power in a regime, and alter the jurisdiction of the regime vis-à-vis that of an individual state.

Vogler (1995), however, states that the existence of a hegemonic leader is not the distinguishing characteristic of an effective regime, but the perception of high levels of mutual vulnerability independence. In this regard, it is not considered viable for the USA, for example, to leave the ITU, as it had UNESCO, due to economic dependence on the vital, global telecommunications infrastructure. Cognizance of this position may lead to compromise, however, equally arguable is that it portends for hegemonic states, notably the USA, to strive for greater influence over other regime members. The interests and activities of states and corporations are often indistinguishable, and Cox (1987) views the senior officials of such institutions as forming a transnational managerial class who have created a globally hegemonic business culture whose interests transcend the state-market dichotomy and are well represented at the ITU, as evident in the US delegation.

\section{UNITED STATES ITU ASSOCIATION}

Although US delegates to the ITU represent US policy, not any particular company or private interest, the fact that all delegates are charged with supporting the documentation that is submitted by the USA is to a large extent immaterial given the crucial role of the private sector in initially formulating the policy. The United States ITU Association (USITUA) was formed in December of 1999 as an open US industry forum for discussion of issues and development of consensus on proposals and views on ITU policy matters that maximize common benefits to the US industry.
The trade association seeks to provide the private sector with a greater voice as it works toward improving ITU processes and improving the US preparatory processes. Fundamentally, the USITUA seeks to develop greater coordination and cooperation between the private sector and the US Government to enhance US effectiveness in the ITU. The views of USITUA are solicited on various issues by the US Department of State, the National Telecommunications and Information Administration (NTIA), and the Federal Communications Commission (FCC), since it is recognized as a vital participant in activities of the US Government that affects private sector interests in ITU-related matters (Rappoport, 2003).

It is important to note in this regard that private corporations in the USA are legally regarded as persons and entitled to the legal rights and protections the Constitution affords to an individual person in accord with the 1886 Supreme Court ruling in the case of Santa Clara County v. Southern Pacific Railroad Company . Corporate influence in molding the policies of the FCC as well as Congressional legislation, such as the Telecommunications Act of 1996, which enabled ever more mergers in the US communications industry, cannot be underestimated. Policies are largely formed in the USA without public participation or public discourse. This model is in essence that which is pursued in the ITU, which supports the contentions of neorealists regarding the influence of hegemonic states, for, ironically, the ITU, while committed to freedom on information, classifies its information and thus prohibits public access and input. Information regarding ongoing work and meetings in the ITU is not publicly available - only to its members. The ITU may well be advised to adopt a Freedom of Information Act to declassify documents before the requisite 20 years. The rhetoric of the ITU withstanding, it can claim no direct accountability to citizens, though it is committed to the inclusion of the corporate class. According to Lee (1996), the vast majority of private sector delegates to the Plenipotentiary Conference, the supreme organ of the ITU, come from the core countries that dominate the global telecommuni- 
cations market, namely, the USA, the UK, Japan, Canada, France and Italy, and, given the decentralized structure of conference proceedings, the influence of these delegates far exceed their actual numbers.

\section{TRIPARTITE STRUCTURE OVERVIEW}

Indeed, 12 of the 28-member panel assigned to formulate recommendations for institutional reform came from leading private sector telecommunications and business organizations (Geri, 2001). Taverns (2000) writes that the panel members urged that the ITU be transformed into a private-public partnership, arguably essential as its PTT political authority has eroded and greater telecommunications deliberations now occur in the liberalization-oriented World Trade Organization. The panel also suggested that the authority and responsibility of the General Secretariat be enhanced and the operations divided among the three functional arms be combined, though this would remove the discretionary power accorded each Sector to ascertain its own institutional responses to its needs and constituents (Taverns, 2000). Although this recommendation was not adopted, it is clear that the architects of the tripartite structure of the ITU lacked the foresight to appreciate the competition and rivalry between the Sectors that would ensue. Parkes (2000) contends that bitter in-fighting deprived ITU Secretary General Utsumi of the senior support he needed. Indeed, each of the individual sector directors vies for the position of Secretary General as their terms expire simultaneously.

Such issues of stability and change have long been of concern to regime theorists, and it should be noted that the creation of the tripartite structure and the change of rules and decision-making procedures within each of the Sectors of the ITU signify the adaptive process of the regime, not actual regime change which would entail an alteration of norms and principles (Vogler, 1995). Reform did not include an alteration of the achievement of consensus, nor the creation of centralized mechanisms to monitor compliance with its instruments. The purposes of the ITU have remained essentially unaltered. There has, however, been a subtle, but fundamental shift of power from nation states, irrespective of their voting status in the Union, to transnational corporations. This is in accord with what Geri (2001) refers to as the New Public Management, in which the state, devoted to securing conditions that enable the domination of multinational firms, engages in administrative reforms which include privatization of state owned enterprises, deregulation, competition in services, and facilitation of the role of the private sector in international organizations. Geri (2001) contends that of all the UN specialized agencies, the ITU is under the most pressure, due to incessant changes in the telecommunications sector and the fear of becoming irrelevant in light of these changes, to implement substantial reforms strengthening the role of non-state stakeholders.

\section{BUDGET}

Although Geri (2001) states that funding issues do not appear to be the driving force for the reforms, the ITU has suffered notable financial duress in recent years. Sector members have certainly assisted in alleviating the ITU's budgetary woes, which accounts in part for the organization's campaign to recruit private companies to become active members and fund its various programs. It need be noted, though, that threatening to reduce one's financial contribution is often employed as a means to change an organization, or at least as a limited retaliation or demonstrated opposition to an organizational decision, as arguably demonstrated by some European firms reducing their ITU contributions when voting rights were denied to sector members.

According to the ITU (2006a), sector members contribute 11.6 percent and associate members, a more limited class of private company participants, contribute 0.6 percent of the overall budget. Notably, other forms of private sector financial contributions account for a further 15.2 percent of total funding, namely, cost recovery for services such as project execution, satellite notifications, and the sale of publications, thus raising total private sector contributions to more than 27 percent of the ITU budget. It should also 
be noted that as a group sector members and associates pay about as much that paid in total by approximately 88 percent of the member states, and that if a sector member joins all three sectors, that sector member pays nearly the amount that 60 percent of the member states pay. This situation is attributed to the lower amounts paid by developing countries.

At each Plenipotentiary Conference, each member and sector member freely selects its class of contribution, from one-sixteenth of a unit to 40 units. When the budget is approved, the amount of the contributory unit is determined, which for the biennium 2006-2007 is set at Swiss Francs or CHF 318,000 per unit. The current value of one contributory unit for a sector member is set at one-fifth of that of a member. Only members listed by the UN as least developed countries and approved by Council may select the one-eighth and one-sixteenth unit classes of contribution. Although the contributory unit for associates has been fixed at CHF 10,600 for the ITU Radiocommunication and Telecommunication Standardization Sectors, the Development Sector is only CHF 3,975 and merely CHF $1,987.50$ for associates from developing countries ([10] ITU, 2006a).

MacLean (2003a) recommends that this freechoice financing scheme of the ITU be replaced in order to secure and solidify its financial position. Furrer (2000) concurs, stating that the ITU's fragile financial position can be strengthened by widening the financial base, lowering the contributory unit to make the ITU affordable to a wider range of actors, and if necessary, forging guidelines on the appropriate level of contributions to prevent sector members from reducing their contribution to the strictest minimum. Since member states cannot be restored to their former position at the center of global governance, MacLean (2003a) contends, reform must entail acceptance of plural centers of power, a new coalition of stakeholders with equal rights and obligations. Furrer (2000) argues that sector members should be given more decisional power, including voting rights, at all levels of ITU activities, particularly regarding finances and budgets. In exchange for being on an equal footing with member states within the Finance Committee, sector members, writes Furrer (2000), should contribute to the ITU's budget on a basis proportionate to their activities and be allowed to allocate financial resources to a specific activity within a sector. Furrer (2000) also proposes that voting procedures should be introduced and applied when consensus cannot be reached.

Enhancing the decision-making rights and financial responsibilities of the private sector in the ITU has been staunchly advocated by Europe, but there is a sharp divergence of opinion regarding the apposite role for the private sector among the different member states. Many members, particularly developing countries, object to the increased involvement and influence of private sector interests in ITU decision-making processes, though they may be amenable if it correlates to greater financial contributions (MacLean, 2003a). The Arab states, however, have submitted proposals in the ITU-R to clearly delineate treaty and non-treaty matters, and to the extent possible, exclude the participation of the sector members from the treaty-making processes (Fisher, 2003), which is in sharp contrast to what has transpired in the ITU-T where power has been effectively transferred from governments to the private sector (Fisher, 2003). Financial pressures have prompted each of the sectors to reassess its working methods and structures to be increasingly efficient, and demarcate the appropriate role for the private sector, which varies significantly between the three sectors.

\section{ITU-T}

In the ITU-T, formerly the International Telephone and Telegraph Consultative Committee (CCITT), sector members have come to play an equal role with governments in determining the agenda for each four-year standardization cycle. Study groups of experts from the private sector, that is, the leading international telecommunication organizations, then conduct the technical work of developing standards and specifications for telecommunications systems, networks and services. Arguably in no other international industry are technical interconnection standards of 
more importance than in telecommunications (Zacher and Sutton, 1996). Until 1989 telecommunications equipment standards were approved only every four years as recommendations by the plenary assemblies of the former CCITT and the CCIR (International Radio Consultative Committee), which was an extremely long time frame given the rapid pace of change in this arena. The exponential growth and convergence of communications technology coupled with competition in standards setting by regional bodies and private sector software developers have served, in part, as the impetus for reform of ITU-T (Vogler, 1995), which, until 2001, required that all standards be approved by member states before they became official, even though most standards were developed in study groups comprised of the private sector (MacLean, 2003a).

To help ensure that the ITU's preeminent role in this realm was not usurped, the Alternative Approval Process (AAP) was then adopted, which enables standards to be approved by the members of the study group that developed them, which is in essence the private sector. Adoption of the AAP has reduced the average time-tomarket of ITU-T's recommendations by six months, for the traditional approval process averaged about 36.2 weeks, while the AAP is concluded in about 9.4 weeks (Fishman, 2003). Some, however, contend that this process is insufficient to curb the ascendance of a diverse range of private sector-led standard bodies and the ITU may become a mere rubber stamp for the outcomes of deliberations within the Global Standards Cooperation Group (Zacher and Sutton, 1996). Regardless of the ITU's ability to retain its historical dominance in the standardization process, it must be noted that the AAP, which is now employed in virtually all Standardization Sector study groups, has enabled the ITU-T to effectively evade the sovereignty principle, which, MacLean (2003a) contends, is no longer germane in the current global governance environment, and since it is from this principle that the ITU institutional framework stems, it is in the very framework of the ITU, its legal foundations, organizational structures and formal decision- making procedures, that the fundamental problems facing the organization lie.

Indeed many consider the reforms instituted in 1992 inadequate, and, in regard to ITU-T, there are proposals, many of which originate in Europe, to further increase the role of the private sector by creating a separate forum, primarily governed and financed by private sector members, for the development of technical standards not involving policy regulatory matters (Fisher, 2003). Separating technical and regulatory functions has long been a source of debate, though, and arguably all decisions have some public policy implications, so drawing the line between those issues in which the industry should have a major voice and those left to the regulators is a constant source of contention, especially as relates to the ITU-R.

\section{ITU-R}

The USA does not support proposals to split the ITU-T or the ITU-R into separate bodies, as it is satisfied with current procedures, and asserts that the tripartite structure is sound. Although the USA has consistently opposed a broad restructuring of the ITU in a way which would equate to member states sharing power on a equal level with the private sector, it does seek to retain extensive private sector participation in conducting the vital research concerning the technical characteristics and operational procedures for terrestrial and space-based wireless services and systems that serves as a basis for the regulatory decisions made at the ITU-R's World Radiocommunication Conferences (WRCs). The work of the R-Sector, that is developing the technical recommendations and treaty instruments governing the allocation and use of the radio frequency spectrum and related orbital resources, is of serious consequence to member states and sector members alike, though member states are the final decision-makers at WRCs, which are now held every three years.

The complex negotiations overseen by the RSector regarding the radio frequency spectrum form legally binding agreements embedded in the Radio Regulations. It is in part for this reason 
that the R-Sector has not adopted the Alternative Approval Process of the ITU-T, since technical recommendations may acquire regulatory status by being incorporated into the Radio Regulations and most ITU-R questions and recommendations are considered to be of an intrinsic policy or regulatory nature (United States Department of State, 2003)). In this same vein, the USA does not support proposals to distinguish between the RSector's treaty and non-treaty work. Indeed, it contends such a distinction is not feasible since key technical and operational elements of treaty instruments cannot be developed, evaluated, and decided on independently of the non-treaty technical underpinnings of the subject matter (USITUA, 2005). Thus, sector members, who play a pivotal role in coordinating the work of the R-Sector with their member states, cannot be excluded from the treaty making processes. The influence of the private sector in defining its respective member state's policies and proposals as part of the preparatory work for a successful WRC varies significantly, and is notably weaker among developing countries, but it is nonetheless of vital importance to have an efficient national as well as regional consultation between the private sector and the government.

The approval of ITU-R recommendations essentially comprises two stages, with the adoption of a text developed in a working party or task group, and then submitted to the member states for final approval. In some cases, due to logistics and expenses associated with traveling, draft recommendations prepared by the working parties cannot be made available in the working languages in time for the study group, so to expedite the process a single language draft may be employed, though this may conceivably exclude some countries from participating. The document is then forwarded at the adoption stage by correspondence when texts in the working languages are available. To hasten the process, a new procedure was developed in 2003 whereby the adoption by the study group and the approval by member states are undertaken concurrently by correspondence using electronic means of communications (USITUA, 2005). This process, while efficient, can prove problematic for devel- oping countries who cannot often participate in the exchange of draft documents since they have inconsistent access to the internet.

\section{ITU-D}

To administer development assistance activities and redress the global imbalance of telecommunications services, the Telecommunications Development Bureau (BDT) was created in 1989. The Bureau is financed by the ITU's regular budget, a change long resisted, writes Lee (1996), by those members who contribute substantially to the budget. Indeed, Fisher (2003) notes that there is concern among Member states as to whether they are receiving full value for the services rendered by the D Sector and the funds allocated to the D Sector, which are approximately the same amount as allocated to the R-Sector. Some question the appropriateness of development activities being in the ITU and suggest that other international treaty organizations undertake the work. A further consideration is MacLean's (2003a) contention that developing countries have not made noteworthy gains in the ITU reform process and their role in the standardization and radiocommunication sectors has not increased significantly as a result of the creation of the D Sector. The D Sector was established at the same time as the ITU embarked on enlarging the rights and obligations of private sector members of the ITU, which is indicative of its adherence to market-led development.

The ITU-D fully embraces neoliberal ideology as it strives to broker partnerships with the private sector with a view to harnessing the commercial drive of the telecommunications industry to address the needs of developing countries (ITU, 2006b). Within the ITU-D, member states, writes Fisher (2003), actively solicit the support of the private sector as they recognize the need for technical expertise, financial support, and educational and training programs, which is not forthcoming from governmental sources. As traditional sources of international development assistance grow increasingly scarce, the ITU-D deems it essential that the private industry play a catalytic role in promoting strategic partnerships 
with developing countries. The ITU's role has shifted from providing technical assistance to advising on a wide range of issues relating to telecommunications sector reform aimed at creating an enabling environment for private investment. While this goal assists capitalism's expansion and may claim indirect benefits for citizens of developing countries, it should not be confused with development.

Development emphasizes the orientation of production towards basic needs, the orientation of distribution of goods and services towards the poor majority, the incorporation of a social dimension into technological research and innovation, and popular participation in a democratic system. The goal of development, that is, the improvement of society through strong economic growth, accompanied by full employment and income distribution favoring the popular classes, has not been clearly identified as part of the ITU$D$ agenda. Rather, the ITU's promotion of universal approaches to telecommunications policies in conjunction with advocating global principles contradicts sustainable, self-reliant development which focuses on local participation in defining and solving community problems, building on the strengths of the society that undertakes it. Development of the periphery is not a goal of capital's strategies, but the ITU situates the telecommunications policies it advocates within a privatized commercial structure, as it likens modernity with the private sector in accord with the dominant paradigm of development.

This view of telecommunications and development as a win-win situation for developing countries and telecommunications service providers alike is espoused by Toure, the former Director of the Development Bureau who was elected as Secretary-General at the ITU Plenipotentiary Conference in November 2006. Toure (2003) writes that "[d]eveloping countries will enjoy increased connectivity and thus improved access to basic as well as enhanced telecommunications services and applications, while US firms will gain market share and earn a reasonable return on investment". He also notes that "[t]he FCC's contribution is most valued by us in the ITU because their leadership has, in part, en- couraged the rapid growth of regulatory authorities" (Toure, 2003). Many telecommunications functions have been assumed by the private sector with governments increasingly limiting themselves to a regulatory and supervisory role, however, for the FCC to serve as a model of an independent regulatory authority for developing countries to emulate is to promote complete transnational corporate control of the sector globally, for the FCC effectively operates outside the light of public attention in the USA and gives but lip service to the "public interest," for otherwise the FCC could not tolerate corporate concentration in the eminent broadcasting and telecommunications industries. US communications policies have shifted dramatically from the country's early years of independence when federal subsidies were allocated to newspapers to ensure a diversity of perspectives, to the domination of a few very large, vertically and horizontally integrated transnational corporations. As McChesney (2004) contends, this cartel structure of the media in the USA coupled with the profitmaximizing commercial orientation of the communications corporations has depoliticized the American public as it utterly undermines the press's role as the fourth estate, and the captured agency of the FCC is impotent to change this, as are most "independent" regulatory agencies in developing countries.

The Regulatory Reform Unit of ITU-D organizes meetings, workshops and training programs for national regulators in developing countries, venues at which the private sector can advance its influence. For one day of the annual Global Symposium for Regulators (GSR), private corporations or sector members are invited to demonstrate new technological innovations and educate regulators in the applications of the emerging technologies. Such education is not a mere presentation of facts, devoid of regulatory context, but arguably spun to meet the market aims of the given manufacturer or service provider. Two days of the GSR are reserved for regulators and policy-makers, but corporate sector members can sponsor coffee breaks, cocktails hours, etc. and thereby extend their influence in these informal gatherings. 
Before these global meetings, regional preparatory meetings are held which are now derived in part from regional working parties (RWP), which were launched in 2004 and are open to all private companies in the information and communications sectors in a given region, not just ITU sector members. Although only ITU sector members can chair the meetings, it does give the opportunity for other private companies to participate in voicing their concerns and priorities for a given region. The stated objectives, for example, of the 2nd Arab regional working party meetings in 2005 were "[t]o elaborate, discuss and consolidate proposals ... [which] should identify concrete BDT programs and activities to be submitted to WTDC-06 (Doha), for inclusion in the next four-year Action Plan. To discuss and elaborate proposals by ARWP to improve and develop participation of Sector members and the private sector in BDT activities and ICT development projects" (Toure, 2005).

\section{CONCLUSIONS}

The ITU actively solicits and supports the ascendance of private corporate actors within each of the three sectors of the organization. In the Standardization Sector, power has been effectively transferred from nation states to the private corporate sector since the approval process now enables standards to be approved by members of the study group that developed them, which is essentially the private sector. In the Radiocommunication Sector, where it is difficult to distinguish between treaty and non-treaty work, the private sector continues to conduct much of the requisite technical work, though national governments remain the final arbitrators. In the Development Sector, the ITU seeks to create an enabling environment for private investment in developing countries as it actively seeks to build private sector partnerships. In essence, its orientation to development is aimed at enhancing corporate opportunities for capital accumulation in developing countries, which, arguably, is neglect of its responsibilities to the global commons. The widely held view of the ITU as a value-neutral, essentially technical UN specialized agency is untenable as its objectives conflict. Over the long term, the ITU may prove unable to satisfy either its narrow corporate constituency or the vast majority of their developing country Members (Geri, 2001). 'Reform' will thus continue to be the ITU mantra.

\section{ACKNOWLEDGEMENTS}

The author would like to thank Howard University for the Social Sciences, Humanities, and Education Grant that facilitated this research.

\section{FOOTNOTES}

1. An article submitted to the Editors-in-Chief of Information Technologies and International Development. A version of it was subsequently published as "The quest for inclusive governance of global ICTs: lessons from the ITU in the limits of national sovereignty, information technologies and international development" (MacLean, 2003b).

\section{REFERENCES}

Cowhey, P. (1990), The international telecommunications regime: the political roots of regimes for high technology, International Organization, 44.2, pp. 169-99.

Cox, R. (1987), Production, Power and World Order: Social Forces in the Making of History, Columbia University Press, New York, NY.

Drake, W. (2000), "The rise and decline of the international telecommunications regime", in Marsden, C.T. (Ed.), Regulating the Global Information Society, Routledge, London, pp. 124-77.

Escobar, A. (1995), Encountering Development: The Making and Unmaking of the Third World, Princeton University Press, Princeton, NJ.

Geri, L. (2001), New public management and the reform of international organizations, International Review of Administrative Sciences, 67.3, pp. 445-60.

Fisher, B. (2003), Chairman's report, The Point Newsletter of the United States ITU Association 8, September, pp. 1-3. 
Fishman, G. (2003), TSAG Results - February 2003, The Point Newsletter of the United States ITU Association 7 , April, pp. 8-10.

Furrer, M. (2000), ITU Reform Advisory Panel - Second Meeting, ITU Ref/15mf, ITU, Geneva, March 3.

International Telecommunication Union (ITU) (2006a), "ITU budget 2006-2007", available at: www.itu .int/aboutitu/budget/2006-2007/index.html (accessed August 19, 2006).

International Telecommunication Union (ITU) (2006b), "Overview - development sector", available at:

www.itu .int/aboutitu/overview/o-d.html (accessed September 10, 2006).

Lee, K. (1996), Global Telecommunications Regulation: A Political Economy Perspective, Pinter, London.

Lyall, F. (1989), Law and Space Telecommunication, Gower, Aldershot.

MacLean, D. (2003a), "Sovereign right and the dynamics of power in the ITU: lesson in the quest for inclusive global governance", Draft 2, March 20.

MacLean, D. (2003b), "The quest for inclusive governance of global ICTs: lessons from the ITU in the limits of national sovereignty", Information Technologies and International Development, 1.1, pp. 1-18.

McChesney, R. (2004), The Problem of the Media: US Communication Politics in the 21st Century, Monthly Review Press, New York, NY.

Parkes, S. (2000), The enemy within, tele.com, 5.6, March 20, pp. 22-3.

Rappoport, G. (2003), Annual meeting of the USITUA, The Point Newsletter of the United States ITU Association 9, December, p. 10.

Taverns, M. (2000), ITU reform plan proposed, Aviation Week and Space Technology, p. 46.

20. Toure, H. (2005), "Ref: MD-227. 2nd Coordination Meeting of the Arab Regional Working Party (ARWP) on Private Sector Issues, Cairo, Egypt, 3-5 May 2005", available at: www.itu.int/ITU-D/partners/Events/2005/

Cairo_May05/Invitation_Cairo.PDF.

Toure, H. (2003), Shaping the future together, The Point Newsletter of the United States ITU Association 9, December, pp. 2-3.
United States Department of State (2003), "US participation in the ITU radiocommunication sector, and in CITEL, PCC II", November 18, available at: http://ftp.fcc.gov/ib/ sand/irb/guidance.html (accessed August 25, 2006).

United States International Telecommunication Union (USITUA) (2005), "USITUA position paper", Draft US Contribution Resolution 106 Working Group, February 8.

Vogler, J. (1995), The Global Commons: A Regime Analysis, John Wiley \& Sons, New York, NY.

Zacher, M. and Sutton, B. (1996), Governing Global Networks, Cambridge University Press, Cambridge. 